Beyond financial performance: A perspective on occupational safety performance in automobile SMEs in Nigeria

Sakariyau, Olalekan Busra $₫$

University Malaysia of Sarawak (UNIMAS), Malaysia (zaksfebunimas@gmail.com)

Latip, Hamrila Abdu

University Malaysia of Sarawak (UNIMAS), Malaysia (alhamrila@feb.unimas.my)

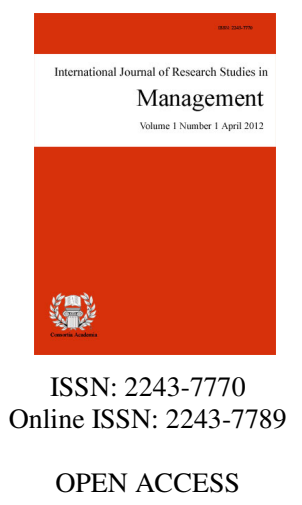

Received: 14 September 2015

Revised: 4 November 2015 DOI: $10.5861 /$ ijrsm.2015.1333

Accepted: 5 November 2015

Available Online: 23 November 2015

\title{
Abstract
}

Previous studies of SMEs have found that accounting, finance, production and marketing take precedence over personnel related issues like safety and health. There has been a long standing interest in finding ways to assist SMEs in improving safety and health. The aim of this study was to assess the occupational safety performance in automobile SMEs in Abuja, Nigeria. The research method is descriptive - survey. The population consisted of all employees in the department of works and maintenance within 46 automobile SMEs. The results indicate that health and safety which is a crucial characteristic and component in the organization need to be improved upon. The entrepreneurs and owners in this enterprise need to inculcate safety leadership supports as part of their strategies to boost employees' health morale and job satisfaction.

Keywords: automobile; small and medium enterprises; safety performance; entrepreneurship; occupational safety 


\section{Beyond financial performance: A perspective on occupational safety performance in automobile SMEs in Nigeria}

\section{Introduction}

To begin with, the root of entrepreneurship stems from the capacity and willingness to develop, organize and manage a business venture along with any of its risks in order to make a profit. Entrepreneurial spirit is characterized by innovation and risk-taking which is an essential part of a nation's ability to succeed in an ever changing and increasingly competitive global marketplace. To compete favorably in global market it goes beyond financial performance and occupational health and safety issues cannot be undermined (Surienty, Hong, \& Hung, 2011; Chan \& Mak, 2012; Ndirangu \& Namusonge, 2014; Eniola, Entebang, \& Sakariyau, 2015; Yaseen \& Okour, 2012).

Knowing the nature and magnitude of health and safety as risks is helpful in setting priorities as well as in making decisions about pursuing high performance in organizations and other aspects of everyday living. Risky situations require a choice among risky alternatives. Determining the level safety in situations involve a more general choice as to how much of other desired activities need to be sacrificed for increased safety. Also situations are inherently more difficult to manage because they are subject to ambiguous thinking and rhetoric (Kvorning, Hasle, \& Christensen, 2015; Sarker, 2014; Dong, 2015).

In modern day work environments, safety management is often viewed as a strategic management tool that can improve a firm's competitiveness, thus indirectly impacting market share, profitability and the firms overall economic and financial performance (Zohar, 2010; Priem, Li, \& Carr, 2012). Safety management has progressed from a traditional approach which focuses solely on hardware and design especially in developed countries, to a modern approach based more on cognitive human factors (Dul 2012; Ball, Carrington, \& Stewart, 2013).

The occupational safety imbalance caused by human actions has forced the major world governments to include safety issues in their agendas. This imbalance is a consequence of non-compliance with international standards and practices. Occupational safety is a serious issue with automobile industry as one of the top ten rated hazardous industry with a persistent increase in accident and injury rates (Christian, Bradley, Wallace, \& Burke, 2009; Hassam \& Mahamad 2012; Vandergrift, Gold, Hanlon, \& Punnett, 2012; Gangloff, 2013;. Agarwal, Garg, \& Jain, 2014). Due to this scenario, previous studies have shown considerable interest in addressing the issue (e.g. Fiebai, \& Awoyesuku, 2011; Ajani, Ajibola, Salau, Odufuwa, \& Odewabi, 2013; Desa, Habidin, Hibadullah, Fuzi, \& Zamri, 2013; Akple, Turkson, Ezugwu, Biscoff, \& Bosrotsi, 2014). Not only this, occupational safety issue has become a global interest and important domain for business researchers including entrepreneurship in the current decade due to the imperativeness that businesses, especially SMEs to add it as part of the values to their services (Rodgers, 2010; Gardner, 2014; Wu \& Huarng, 2014). Also, it is part of occupational safety obligations to achieve both business ambitions and sustainable world (Smith, Voß, \& Grin, 2010).

\section{Literature Review}

The automobile industry is a prosperous occupation that employs one of highest proportions of young workers below the age of 25 years (Pavlínek \& Ženka, 2011; Sturgeon \& Biesebroeck, 2011; Markard, Raven, \& Truffer, 2012; Wells \& Nieuwenhuis, 2012). However, workers in this trade generally have the highest risk of occupational injury and hazards (Ashok, 2012; Sripathi Raja, Siva Prakash, Vellaichamy, Senthil Kumar, \& Palani, 2013; Agarwal, Garg, \& Jain, 2014). Furthermore, workers in a hazardous occupation like automobile maintenance and repair are at even higher risk for occupational injury (Hariri, Leman, Yusof, Zainal, \& Paiman, 2012). In Nigeria, a worker is killed every three days and an average of 45 workers is injured each day in an 
A perspective on occupational safety performance in automobile SMEs in Nigeria

automobile industry related incident (Sambo, Idris, \& Shamang, 2012; Idubor \& Oisamoje, 2013). Likewise, government regulations across the globe on automobile safety, emissions, and fuel economy are contradictory. For instance, safety equipment and emissions control reduce fuel economy, reducing the size of automobiles is estimated to increase fatalities by 1400 a year and significantly increase serious injuries (Bae \& Benítez-Silva, 2013).

Safety implies a state of being protected from any risk, danger, damage or cause of injury. Safety in the automobile industry is particularly important and therefore needs to be regulated. The industry has been considered to be the most risky and hazardous in Occupational Health and Safety (OHS) (Singh \& Siddiqui 2014). In the automotive industry, safety means that users, operators or manufacturers do not face any risk or danger coming from the motor vehicle or its spare parts. Safety for the automobiles themselves implies that there is no risk of damage to both vehicles and employees (Parker, Axtell, \& Turner, 2001).

A number of studies were carried out on automobile industry in relation to safety issues. The prominent ones among them pointed out that the industry is characterized with high hazards and accident rate. Despite the fact that law and ethics relating to occupational safety are in place, the revelations from studies suggest that they are poorly implemented. Current workers in the field of automobile will directly or indirectly impact the safety of automobile workplaces if they are well managed. Although many employees have some automobile safety experiences, previous studies have reported that not all of these experiences are positive in terms of safety performances and practices (Johnston 2010; Black et.al 2011; Jin, Lundteigen, \& Rausand, 2011). Yet, little research has investigated the magnitude of occupational practices of workers in the automobile work environment.

\subsection{Automobile and Occupational Safety in Nigeria}

In Nigeria, Onunkwor, Dosumu, Odukoya, Arowolo, and Ademuyiwa (2004), disclosed the huge ameliorative effects of ascorbic acid in chronic lead poisoning among petrol station attendants and auto-mechanics as a result of occupationally exposed lead. In other study, Udonwa, Uko, Ikpeme, Ibanga, and Okon (2009) recommended legislation to be put in place on mandatory provision of personal protection and monitoring for auto mechanic as a result of exposure to risk of premium motor spirit. Similarly, Achuba and Nwokogba (2015), concluded that auto mechanics and fuel attendants are exposed to gasoline vapor leading to decreased haematological indices and at risk of developing anemia. Going out of employees occupational hazards to the environmental issues, Nwachukwu, Feng, and Achilike (2010), disclosed that heavy metal pollution of soil due to poor waste management is causing serious ecological and public health problem. It is on this note that the article aim to assess the level of safety performance in automobile SMEs in Nigeria with focus on three essential cardinals; Occupational Accidents, Injury and Health information.

Sabitu, Iliyasu, and Dauda (2009), revealed that panel bitters and body work workers are exposed to a variety of occupational hazards with untoward health effects. However, the authors observed that little is known of their awareness on health hazards and their adherence to safety precautions. To fill this gap, this study assessed the awareness of occupational hazards and adherence to safety measures among automobile workers in Kaduna metropolis in northern Nigeria by employing a structured questionnaire. The result shows that all workers were males with a mean age of $35.7+/-8.4$ years. The illiteracy rate was $7.6 \%$. Overall, $257(77.9 \%)$ of the welders were aware of one or more workplace hazards. This was positively influenced by their educational background, age, nature of training and work experience. Of the 330 respondents, $282(85.3 \%)$ had experienced one or more work-related accidents in the preceding year. The most common injuries sustained were cut/injuries to the hands and fingers (38.0\%), back/waist pain (19\%), arc eye injuries/foreign bodies (17.0\%), burns (14.0\%), hearing impairment (7.0\%), fractures (4.0\%) and amputation (1.0\%). Only $113(34.2 \%)$ welders used one or more types of protective device, with eye goggles $(60.9 \%)$, hand gloves $(50.3 \%)$ and boots $(34.5 \%)$ being the most frequently used. 
In this respect, Sambo, Idris, and Shamang (2012), identified the determinants of occupational health hazards and determined the level of their knowledge and practice on the use of personal protective equipment. The study shows that training type, duration of training, years of experience and level of awareness of protective device are the major determinants of occupational hazards among roadside automobile mechanics. Also there was a high level of awareness but low usage of protective device among respondents. Hence, there is need for emphasis on health education through programs promoting work place safety among automobile workers.

Similarly, Ajani et al., (2013) analyzed the risk of cardiovascular and hepatic injury incurred by people engaged in jobs such as mechanics and other related automobile work. The quantitative results showed that the triglyceride level, artherogenic and coronary risk index of the automobile workers were higher than the control group. Awodele, Sulayman, and Akintonwa, (2014), assessed the use of available control measures/initiatives in selected automobile and allied companies. The results showed that $90 \%$ of the respondents reported symptoms relating to hazard exposure. The authors emphasized that the need to develop effective frameworks that will initiate the integration and ensure implementation of safety regulations is paramount.

Olagbegi, Kwasi-Effah, and Ugbi (2013), elaborated on whether the automobile industry is maintaining a safe working environment. The result of his study revealed that there is a low level of health and safety practices in the workshop as a result of the lack of maintenance practices and improper measures to prevent health damage. Similarly, Ezejiofor, Nwigwe,Osuala, and Iwuala(2014), linked working environment with environmental metals pollutants. The results indicated that the mean concentrations for most of the metals were high compared to the standards set by the Nigerian Federal Environmental Protection Agency (FEPA) and World Health Organization (WHO). Findings in this study revealed that the pollutants have serious implications on public health.

James, Moses, and Vandi (2014) correlated the measurement of environmental radiation in an automobile mechanic village with the health of the people living and working within the area. The result of his study indicated that the automobile technicians, craftsmen and the people living and working within the area are safe and are not exposed to the high doses of radiation as a result of activities in the Apo Automobile Mechanic Village, although the result cannot be generalized based on the segment selected.

Overall, it can be deduced from these studies that the level of awareness of occupational hazards was high but with sub-optimal utilization of protective measures against the hazards. Therefore, the need for health and safety education for employees in this industry is paramount. This leads us to safety performance.

\section{Methodology}

This section presents data from self-administered questionnaires collected from technicians, electrician, mechanics, welders and engineers in the department of works and maintenance across 46 automobile SMEs in Abuja, Nigeria. These groups of people are considered because they are more at risk of facing occupational accidents and hazards in the workplace, specifically in Small and Medium Automotive Enterprises in Nigeria. A number of strategies were considered to ensure high response rate of the survey. Firstly, the respondents were guaranteed of the confidentiality of the research. Secondly, the questionnaire was kept relatively short to improve response rates as these strategies were effective for higher response rates as claimed by (Bryman \& Bell, 2011, p. 235). The purpose of the research was made clear for the respondents in the letter of introduction attached with questionnaire.

A total of 300 questionnaires were distributed to employees in the department of repairs and maintenance within 46 SMEs automotive enterprises in Abuja, Federal capital city of Nigeria. The total of 270 questionnaires was returned and 20 of which were excluded because of several missing pieces of data per case. The cases with missing data were discarded if they comprised less than 250 fully filled questionnaires, which represented $83.33 \%$ of the total number of questionnaires distributed. This response rate was considered adequate for the following reasons: firstly, the data were collected in a self-administered manner, with no prior contact or personal connection made with the employees in the automotive industry. Secondly, the total number of 
A perspective on occupational safety performance in automobile SMEs in Nigeria

responses were greater than that suggested by Bartlett, Kotrllk, and Higgins (2001) for regression type analysis, that is, the sample size should be between five and ten times the number of the independent variables. Thirdly, a review of the published social research literature suggests that a response rate of at least $50 \%$ can be considered adequate for analysis and reporting (Anderson, Richardson, McKie, Iezzi, \& Khan, 2009; Babbie, 2007).

The response rate of this study is considered high with $83 \%$ compared to previous studies conducted in occupational safety studies: Hussein (2008) achieved a 32\% response rate, Al-Jubouri (2009) achieved a 44\% response rate, Ali and Mohammed (2010) achieved a 49\% response rate, and Abdullah (2011) achieved a 50\% response rate. Table 1 below shows the itemized response rates of distributed questionnaires.

\section{Table 1}

Response Rate of Questionnaire

\begin{tabular}{lc}
\hline \multicolumn{1}{c}{ Response } & Frequency / Rate $(n=250)$ \\
\hline Number of Questionnaire distributed & 300 \\
Number of Questionnaire returned & 270 \\
Usable Questionnaire Returned & 250 \\
Excluded Questionnaire & 20 \\
Questionnaire not returned & 000 \\
Response rate & $90 \%$ \\
Usable response rate & $83.33 \%$ \\
\hline
\end{tabular}

Prior to reporting the main findings of the survey, the demographic characteristics of the participants are considered necessary. The use of detection of out-of-range values can be achieved using descriptive analysis and the frequency method (Dillon, Madden, \& Firtle, 1990). These methods were employed to provide an overall assessment of the population of employees in Automotive SMEs in Nigeria. Demographic characteristics include job, gender, age, education, marital status, accidents encountered, and experience.

Table 2

Demographic characteristics of Automotive SMEs in Nigeria $(N=250)$

\begin{tabular}{|c|c|c|c|}
\hline Measure & Items & Frequency & Percentage $(\%)$ \\
\hline \multirow[t]{2}{*}{ Gender } & Male & 230 & 92 \\
\hline & Female & 20 & 18 \\
\hline \multirow[t]{4}{*}{ Age group } & $20-29$ & 80 & 32 \\
\hline & $30-39$ & 100 & 40 \\
\hline & $40-49$ & 50 & 20 \\
\hline & $>49$ & 20 & 8 \\
\hline \multirow[t]{4}{*}{ Job } & Mechanics & 130 & 52 \\
\hline & Electrician & 80 & 32 \\
\hline & Panel bitter \&Painter & 30 & 12 \\
\hline & Others & 10 & 4 \\
\hline \multirow[t]{5}{*}{ Education } & Secondary certificate & 90 & 36 \\
\hline & Trade certificate & 95 & 38 \\
\hline & Diploma & 40 & 16 \\
\hline & Degree & 19 & 7.6 \\
\hline & Post graduate & 6 & 2.4 \\
\hline \multirow[t]{2}{*}{ Marital status } & Married & 190 & 76 \\
\hline & Single & 60 & 24 \\
\hline
\end{tabular}

Table 2 indicates that majority of the participants were mechanics (52\%). Other participants were Electrician (32\%), panel bitter \& painter $(12.0 \%)$ and others (4\%). As regards to the gender of the participants; most of them were male $(93 \%)$, while only $7 \%$ were female. This observation indicates the dominance of male employees in automotive SMEs in Nigeria, which is similar to most automotive industries in the world.

Pertaining the age matter, results showed that the highest number of participants were between 30 to 39 years old (40\%), followed by the age group of 20 to 29 years old (32\%), 40 to 49 years old (20\%), and 49 years 
Sakariyau, O. B., \& Latip, H. A.

old and above (8\%). Thus, majority of the participants had considerable work experience. For the education level of participants $(36 \%)$ of them had secondary school certificate, $(38 \%)$ had Technical \& Trade certificate, $(16 \%)$ had diploma, (7.6\%) had Bachelor's degree and $2.4 \%$ had Master's degree or equivalent.

\subsection{Occupational Accidents and frequency of its Occurrence}

Table 3 shows the result of the participants' response to the occurrence of occupational accident since the starting of the work in the company. The result revealed that 53 participants $(21.2 \%)$ claimed that they have had experienced occupational accident since they started working in the company, while 197 participants (78.8\%) claimed that they have not had any occupational accident since they started working in the company. From this table, it is obvious that accident occurs although with less than 50\% from the sample employees. Yet, "an injury to one is an injury to all".

Table 3

Perception on the occurrence occupational accident since the starting of the work in the company $(N=250)$

\begin{tabular}{cccc}
\hline Occupational Accident & & Frequency & Percent \\
\hline Yes & & 53 & 21.2 \\
No & & 197 & 78.8 \\
& Total & 250 & 100.0 \\
\hline
\end{tabular}

\subsection{Frequency of Occupational Accidents}

Table 4 shows the result of the response of the participants to the number accidents they were involved in while working in the company. The result reflects that 35 participants $(67.1 \%)$ were involved in accidents 1-3 times; 14 participants $(25.4 \%)$ were involved in accidents $4-8$ times; 3 participants $(5.6 \%)$ were involved in accidents $9-15$ times and only one participant was involved in ascendants of more than 15 times.

From the table, it shows that level of occupational safety is low. Safety is paramount and organizations should strive for zero accident as accident occurrences can claim the life of the most indispensable employee in the organization.

\section{Table 4}

Perception of the participants to number accidents involved in while working in the company $(N=250)$

\begin{tabular}{|c|c|c|}
\hline No of Accidents & Frequency & Percentage \\
\hline 1-3 Times & 169 & 67.6 \\
\hline 4-8 Times & 68 & 27.2 \\
\hline 9-15 Times & 10 & 4.0 \\
\hline More than 15 Times & 3 & 1.2 \\
\hline Total & 250 & 100.0 \\
\hline
\end{tabular}

\subsection{Perceived Safety at Work}

Table 5 shows the response of the participants to perceived safety at work. From the result, 110 participants (44\%) claimed that the current situation at work is very safe; 92 participants (36.8\%) claimed that the current situation at work is moderately safe; 26 participants $(10.4 \%)$ are neutral in respect of the current situation at work; 18 participants (7.2\%) claimed that the current situation at work is moderately unsafe; and 4 participants $(1.6 \%)$ claimed that the current situation at work is very unsafe.

This result shows that less than 50\% of sample employees perceived very safe. This is a very poor situation and unwanted safety performance because the safety of job determines it sustainability. 
A perspective on occupational safety performance in automobile SMEs in Nigeria

Table 5

Perception of the participants on safety at work $(N=250)$

\begin{tabular}{|c|c|c|}
\hline Participants perception on safety at work & Frequency & Percentage \\
\hline Very Safe & 110 & 44.0 \\
\hline Moderately Safe & 92 & 36.8 \\
\hline Neutral & 26 & 10.4 \\
\hline Moderately Unsafe & 18 & 7.2 \\
\hline Very Unsafe & 4 & 1.6 \\
\hline Total & 250 & 100.0 \\
\hline
\end{tabular}

\subsection{Number of Accidents in the Last Twelve Months}

Table 6 below shows the response of the participants to the number of accidents they were involved in, in the past twelve months. The result revealed that 206 participants (82\%) were not involved in any accident in the last twelve months; 26 participants $(10.4 \%) \%$ ) were involved in only one accident in the last twelve months; and 18 participants $(7.2 \%)$ were involved in two accidents within the said period of time. Unlike any other measure of performance, occurrence of $20 \%$ in a year according to the data gathered shows that the sector is poor in safety performance level. One can infer from the result that other hazards are in place as well which employees might not even be aware of.

\section{Table 6}

Response of the participants to the number of accidents they were involved in in the last twelve months $(N=250)$

\begin{tabular}{lcc}
\hline \multicolumn{1}{c}{ Accident/s in the last twelve months } & Frequency & Percent \\
\hline No Accident & 206 & 82.4 \\
One Accident & 26 & 10.4 \\
Two Accidents & 18 & 7.2 \\
Total & 250 & 100.0 \\
\hline
\end{tabular}

\subsection{Injury, Hazard and Health Information}

Table 7 shows the result of the participants' response to injury, hazard and health information. The result revealed that at all the time, 110 participants (44.0\%) were full of encouragement; 117 participants (46.8\%) had a lot of energy; 17 participants $(6.8 \%)$ felt worn out and 17 participants $(6.8 \%)$ felt tired. However, most of the time, 71 participants $(28.4 \%)$ were full of encouragement; 80 participants $(32.0 \%)$ had a lot of energy; 33 participants $(13.2 \%)$ felt worn out and 22 participants $(8.8 \%)$ felt tired. Similarly, in a good bit of time, 22 participants $(8.8 \%)$ were full of encouragement; 21 participants $(8.4 \%)$ had a lot of energy; 60 participants (24.0\%) felt worn out and 48 participants (19.2\%) felt tired. Besides, some of the time, 129 participants (10.0\%) were full of encouragement; 32 participants $(12.8 \%)$ had a lot of energy; 17 participants $(51.6 \%)$ felt worn out and 158 participants $(63.2 \%)$ felt tired. Finally, for a little bit of the time, 22 participants $(8.8 \%)$ felt of encouragement; 11 participants (4.4\%) felt worn out and 5 participants (2.0\%) felt tired. From the above analysis, less than $50 \%$ of employees were full of encouragement and had enough energy to work with. This is a discouraging situation as it affects the morale of the employees. This adequately informs the industry and its stakeholders that there is a low level of safety performance.

\section{Table 7}

Participants' response to the injury, hazard and health information

\begin{tabular}{lcccccccccc}
\hline & $\mathrm{F}$ & $\%$ & $\mathrm{~F}$ & $\%$ & $\mathrm{~F}$ & $\%$ & $\mathrm{~F}$ & $\%$ & $\mathrm{~F}$ & $\%$ \\
\hline Full of encouragement & 110 & 44.0 & 71 & 28.4 & 22 & 8.8 & 25 & 10.0 & 22 & 8.8 \\
Having a lot of energy & 117 & 46.8 & 80 & 32.0 & 21 & 8.4 & 32 & 12.8 & -- & - \\
Feel worn out & 17 & 6.8 & 33 & 13.2 & 60 & 24.0 & 129 & 51.6 & 11 & 4.4 \\
Feel tired & 17 & 6.8 & 22 & 8.8 & 48 & 19.2 & 158 & 63.2 & 5 & 2.0 \\
\hline
\end{tabular}

Note. $\mathrm{F}=$ frequency 


\section{Conclusion}

The article discussed the level of safety performance in relation to safety at work, accident occurrence, injury and health information in the automobile SMEs Nigeria. Firstly, it can be observed that the perception of employees on the occurrence of occupational accident since their commencement of work in the company is not good. Almost 50\% revealed that they are victims of occupational accident. This is in line with earlier studies that have highlighted that the industry is not an accident free enterprise. Irrespective of the percentage of victims involved, "an injury to one is an injury to all". Also the information from the participants on the number of accidents showed that they were involved while working in the company. The result revealed that at least $67 \%$ were involved in accidents 1-3 times from the time they have joined the company. This further highlight that safety which ought to be of paramount concern is yet to occupy its position in the automobile SMEs industry in Nigeria.

\subsection{Implication for Policy}

Apparently the Occupational Health and Safety policy covers almost all the requirements on occupational safety related matters, but no further evidence was found to check the practical applicability or reality of review and continual improvement requirements mentioned in this policy. Also, there is no review of OHS policy in place to meet the current situation as well as in line with the development of technological advancement since after it was developed. Therefore, the whole point is for government to have a careful examination of these workplaces, define potential risks and also put sensible measures on how to control, monitor and ensure that the risks are consistently controlled. The key issue is that government should have a step-by-step guidance for enterprises, and then of course record and utilize the findings and output of research order for review and auditing.

\subsection{Future Research and Limitations}

This paper only focused on the assessment of safety status of employees as non- financial performance measure of organization so there needs to be further research to come up with both internal and external measures that could guarantee maximum safety in the industry. Other category of high-rated hazardous industry can also be investigated in the future research. Suggestions for future research within the SMEs especially automobile industry could revolve around investigating the reasons why employees do not pursue standardized safety practices concerning their business actions.

Furthermore, in relation to perception of employees on safety at work, only $44 \%$ claimed that the current situation at work is very safe. This shows that an employee who goes out to earn a living cannot guarantee that he could come back to meet his family safely. This sad revelation is in parallel to the responses of the sampled employees on the number of accidents involved in last twelve months. This result revealed that at least $18 \%$ claimed to have involved in an accident or injury in the last twelve months.

Also, another angle of safety issue addressed in the study is hazard and health information. The result obtained through the sampled employees revealed that only $44 \%$ of the employees were full of encouragement and $56 \%$ felt worn out and tired most of the time. This is not a good signal to this sector because if the result persists in this direction, it means the sector would no longer be lucrative to existing and potential employees. This is discouraging situation as it affects the morale of the employees.

\section{References}

Abdullah, T. (2011). Study the economics of oil in the light of economic variables. Journal of Economic Sciences, $42,78-92$.

Achuba, F. I., \& Nwokogba, C. C. (2015). Effect of honey supplementation on heamatological parameters of wistar albino rats fed hydrocarbon contaminated diets. Biokemistri, 27(1), 44-49. 
A perspective on occupational safety performance in automobile SMEs in Nigeria

Agarwal, P. K., Garg, S., \& Jain, V. (2014). A statistical approach for identification of hazardous locations in a road network. Journal of Advanced Research in Automotive Technology and Transportation System, 1(1), 1-13.

Ajani, E. O., Ajibola, A., Salau, B. A., Odufuwa, T. K., \& Odewabi, A. O. (2013). Preliminary report on hepatic and cardiovascular risk assessment of automobile mechanics in Nigeria. African Journal of Biotechnology, 10(9), 1705-1711.

Akple, M. S., Turkson, R. F., Ezugwu, C. I., Biscoff, R. K., \& Bosrotsi, C. K. (2014). An empirical investigation into the relationship between workshop operations and accidents in local automobile garages in Ghana. Journal of Advances in Environmental Health Research, 2(3), 142-150.

Ali, A. M., \& Mohammed, K. G. (2010). Study the behavior of accountants in the sector of oil and gas. Journal of Business Administration and Accounting, 19(1), 185-106.

Al-Jubouri, Y. (2009). Study of individual differences and skills for workers in companies of Iraqi oil. Journal of Administrative Sciences and economic, 42(3), 55-65.

Anderson, M., Richardson, P. J., McKie, J., Iezzi, A., \& Khan, M. (2009).The relevance of personal characteristics in health care rationing: What the Australian public thinks and why. Centre for Health Economics, 42, 1-19.

Ashok, K. A. (2012). A study of employees' welfare, industrial accidents and safety measures with special reference to MIDC, Baramati. Journal of Biological Chemistry, 271(20). Retrieved from http://www.aygrt.isrj.net/UploadedData/1411.pdf

Awodele, O., Sulayman, A. A., \& Akintonwa, A. (2014). Evaluation of haematological, hepatic and renal functions of petroleum tanker drivers in Lagos, Nigeria. African Health Sciences, 14(1), 178-184. http://dx.doi.org/10.4314/ahs.v14i1.27

Babbie, E. (2007). The practice of social research (11 $1^{\text {th }}$ ed.). Belmont, CA: Wadsworth.

Bae, Y. K., \& Benitez-Silva, H. U. G. O. (2013). The effects of automobile recalls on the severity of accidents. Economic Inquiry, 51(2), 1232-1250. http://dx.doi.org/10.1111/j.1465-7295.2011.00425.x

Ball, J., Carrington, M. J., \& Stewart, S. (2013). Mild cognitive impairment in high-risk patients with chronic atrial fibrillation: A forgotten component of clinical management? Heart, 99(8), 542-547. http://dx.doi.org/10.1136/heartjnl-2012-303182

Bartlett, J. E., Kotrllk, D. W., \& Higgins, C. C. (2001). Organizational research: Determining appropriate sample size in survey research. Information Technology, Learning, and Performance Journal, 19, 43-50.

Black, A. D., Car, J., Pagliari, C., Anandan, C., Cresswell, K., Bokun, T., .., \& Sheikh, A. (2011). The impact of eHealth on the quality and safety of health care: A systematic overview. PLoS Medicine, 8(1). Retrieved from

http://www.plosmedicine.org/article/fetchObject.action?uri=info:doi/10.1371/journal.pmed.1000387\&re presentation=PDF http://dx.doi.org/10.1371/journal.pmed.1000387

Bryman, A., \& Bell, E. (2011). Business research methods ( $3^{\text {rd }}$ ed.). Oxford university press.

Chan, S. C., \& Mak, W. M. (2012). High performance human resource practices and organizational performance: the mediating role of occupational safety and health. Journal of Chinese Human Resource Management, 3(2), 136-150. http://dx.doi.org/10.1108/20408001211279238

Christian, M. S., Bradley, J. C., Wallace, J. C., \& Burke, M. J. (2009). Workplace safety: A meta-analysis of the roles of person and situation factors. Journal of Applied Psychology, 94, 1103-1127. http://dx.doi.org/10.1037/a0016172

Desa, A. F. N. C., Habidin, N. F., Hibadullah, S. N., Fuzi, N. M., \& Zamri, F. I. M. (2013). Occupational Safety and Health Administration (OSHA) practices and OSHA performance in Malaysian automotive industry. Journal of Studies in Social Sciences, 4(1), 1-15.

Dillon, W. R., Madden, T. J., \& Firtle, N. H. (1990). Marketing research in a marketing environment (2nd ed.). Homewood, IL: Richard D. Irwin Inc.

Dong, T. T. M. (2015). The knowledge, attitude, and practice of consumers towards food safety issues: A review Taiwan. International Journal of Research Studies in Management, 4(2), 13-22. 
Sakariyau, O. B., \& Latip, H. A.

http://dx.doi.org/10.5861/ijrsm.2015.976

Dul, J., Bruder, R., Buckle, P., Carayon, P., Falzon, P., Marras, W. S., ... \& van der Doelen, B. (2012). A strategy for human factors/ergonomics: developing the discipline and profession. Ergonomics, 55(4), 377-395. http://dx.doi.org/10.1080/00140139.2012.661087

Eniola, A., Entebang, H., \& Sakariyau, O. B. (2015). Small and medium scale business performance in Nigeria: Challenges faced from an intellectual capital perspective. International Journal of Research Studies in Management, 4(1), 59-71. http://dx.doi.org/10.5861/ijrsm.2015.964

Ezejiofor, T., Nwigwe, H. C., Osuala, F., \& Iwuala, M. (2014). Appraisals for potential hazards in the operational environment and facilities of petroleum refining and distribution industry in Nigeria. Journal of Medical Investigations and Practice, 9(1), 39-42.

Fiebai, B., \& Awoyesuku, E. A. (2011). Ocular injuries among industrial welders in Port Harcourt, Nigeria. Clinical Ophthalmology, 5, 1261-1263. http://dx.doi.org/10.2147/OPTH.S20297

Gangloff, A. (2013). Safety in accidents: Hugh dehaven and the development of crash injury studies. Technology and Culture, 54(1), 40-61. http://dx.doi.org/10.1353/tech.2013.0029

Gardner, D., Laird, I., Dickinson, P., Legg, S., McBride, D., \& McLaren, S. (2014). Safety climate, attitudes to noise management and exposure to noise in small and medium sized workplaces in New Zealand. Small Enterprise Research, 21(2), 190-201. http://dx.doi.org/10.1080/13215906.2014.11082087

Hariri, A., Leman, A. M., Yusof, M., Zainal, M., \& Paiman, N. A. (2012). Preliminary measurement of welding fumes in automotive plants. International Journal of Environmental Science and Development, 3(2), 146-151. http://dx.doi.org/10.7763/IJESD.2012.V3.205

Hassam, S. F., \& Mahamad, K. A. K. (2012, September). A study of occupational safety hazards: Safety and health issues in automotive industry. In Statistics in Science, Business, and Engineering (ICSSBE), 2012 International Conference on (pp. 1-6). IEEE.

Hussein, A. (2008). Modalities of distribution of petroleum products in local markets. Journal of Administrative Sciences, 12(2), 132-144.

Idubor, E. E., \& Oisamoje, M. D. (2013). An exploration of health and safety management issues in Nigeria's effort to industrialize. European Scientific Journal, 9(12), 154-169.

James, I. U., Moses, I. F., \& Vandi, J. N. (2014). Measurement of Gamma Radiation in an Automobile Mechanic Village in Abuja, North Central, Nigeria. Journal of Applied Sciences and Environmental Management, 18(2), 293-298. http://dx.doi.org/10.4314/jasem.v18i2.21

Jin, H., Lundteigen, M. A., \& Rausand, M. (2011). Reliability performance of safety instrumented systems: A common approach for both low-and high-demand mode of operation. Reliability Engineering \& System Safety, 96(3), 365-373. http://dx.doi.org/10.1016/j.ress.2010.11.007

Johnston, L. (2010). Beyond best practice road safety thinking and systems management- A case for culture changes research. Safety Science, 9(48), 1175-1181. http://dx.doi.org/10.1016/j.ssci.2009.12.003

Kvorning, L. V., Hasle, P., \& Christensen, U. (2015). Motivational factors influencing small construction and auto repair enterprises to participate in occupational health and safety programs. Safety Science, 71, 253-263. http://dx.doi.org/10.1016/j.ssci.2014.06.003

Markard, J., Raven, R., \& Truffer, B. (2012). Sustainability transitions: An emerging field of research and its prospects. Research Policy, 41(6), 955-967. http://dx.doi.org/10.1016/j.respol.2012.02.013

Ndirangu, M. W., \& Namusonge, G. S. (2014). Factors influencing implementation of occupational health and safety: A case study of Kenya vehicle manufacturers in Thika. International Journal of Social Sciences and Entrepreneurship, 1(11), 606-619.

Nwachukwu, M. A., Feng, H., \& Achilike, K. (2010). Integrated study for automobile wastes management and environmentally friendly mechanic villages in the Imo River basin, Nigeria. African Journal of Environmental Science and Technology, 4(4), 234-249.

Olagbegi, P. O., Kwasi-Effah, C. C., \& Ugbi, B. A. (2013). Assessment of health and safety practice in engineering workshop. International Journal of Engineering Sciences, 2(7), 297-301.

Onunkwor, B., Dosumu, O., Odukoya, O. O., Arowolo, T., \& Ademuyiwa, O. (2004). Biomarkers of lead exposure in petrol station attendants and auto-mechanics in Abeokuta, Nigeria: Effect of 2-week 
A perspective on occupational safety performance in automobile SMEs in Nigeria

ascorbic acid supplementation. Environmental toxicology and pharmacology, 17(3), 169-176. http://dx.doi.org/10.1016/j.etap.2004.04.003

Parker, S. K., Axtell, C. M., \& Turner, N. (2001). Designing a safer workplace: Importance of job autonomy, communication quality, and supportive supervisors. Journal of Occupational Health Psychology, 6, 211 -228. http://dx.doi.org/10.1037/1076-8998.6.3.211

Pavlínek, P., \& Ženka, J. (2011). Upgrading in the automotive industry: firm-level evidence from Central Europe. Journal of Economic Geography, 11(3), 559-586. http://dx.doi.org/10.1093/jeg/lbq023

Priem, R. L., Li, S., \& Carr, J. C. (2012). Insights and new directions from demand-side approaches to technology innovation, entrepreneurship, and strategic management research. Journal of Management, 38(1), 346-374. http://dx.doi.org/10.1177/0149206311429614

Rodgers, C. (2010). Sustainable entrepreneurship in SMEs: A case study analysis. Corporate Social Responsibility and Environmental Management, 17(3), 125-132. http://dx.doi.org/10.1002/csr.223

Sabitu, K., Iliyasu, Z., \& Dauda, M. M. (2009). Awareness of occupational hazards and utilization of safety measures among welders in Kaduna metropolis, Northern Nigeria. Annals of African Medicine, 8(1), 46-51. http://dx.doi.org/10.4103/1596-3519.55764

Sambo, M. N., Idris, S. H., \& Shamang, A. (2012). Determinants of occupational health hazards among roadside automobile mechanics in Zaria, North Western Nigeria. Borno Medical Journal, 9(1), 5-9.

Sarker, M. A. R. (2014). Occupational Health and Safety (OHAS) crisis in tanneries of Bangladesh: Is this the violation of labor rights? European Journal of Business and Management, 6(16), 165-169.

Singh, D., Hasan, S., Siddiqui, S., Kulshreshtha, M., Aggarwal, T., \& Agarwal, S. (2014). Eosinophil count in petrol pump workers in and around the Muzaffarnagar City. National Journal of Physiology, Pharmacy and Pharmacology, 4(2), 118-120. http://dx.doi.org/10.5455/njppp.2014.4.290920132

Smith, A., Voß, J. P., \& Grin, J. (2010). Innovation studies and sustainability transitions: The allure of the multi-level perspective and its challenges. Research Policy, 39(4), 435-448. http://dx.doi.org/10.1016/j.respol.2010.01.023

Sripathi Raja, J., Siva Prakash, M., Vellaichamy, N., Senthil Kumar, K. L., \& Palani, K. (2013). Hazard Identification and risk assessment in new chassis assembly line. Applied Mechanics and Materials, 376, 468-475. http://dx.doi.org/10.4028/www.scientific.net/AMM.376.468

Sturgeon, T. J., \& Biesebroeck, J. V. (2011). Global value chains in the automotive industry: an enhanced role for developing countries? International Journal of Technological Learning, Innovation and Development, 4(1), 181-205.

Surienty, L., Hong, K. T., \& Hung, D. K. M. (2011). Occupational safety and health (OSH) in SMEs in Malaysia: A preliminary investigation. Journal of Global Entrepreneurship, 1(1), 65-75.

Udonwa, N. E., Uko, E. K., Ikpeme, B. M., Ibanga, I. A., \& Okon, B. O. (2009). Exposure of petrol station attendants and auto mechanics to premium motor sprit fumes in Calabar, Nigeria. Journal of Environmental and Public Health. http://dx.doi.org/10.1155/2009/281876

Vandergrift, J. L., Gold, J. E., Hanlon, A., \& Punnett, L. (2012). Physical and psychosocial ergonomic risk factors for low back pain in automobile manufacturing workers. Occupational and Environmental Medicine, 69(1), 29-34. http://dx.doi.org/10.1136/oem.2010.061770

Wells, P., \& Nieuwenhuis, P. (2012). Transition failure: understanding continuity in the automotive industry. Technological Forecasting and Social Change, 79(9), 1681-1692. http://dx.doi.org/10.1016/j.techfore.2012.06.008

Yaseen, Z., \& Okour, A. (2012). Managing organizational change: Decision's maker perceptions in the UAE manufacturing industry. International Journal of Research Studies in Management, 1(1), 97-108. http://dx.doi.org/10.5861/ijrsm.2012.v1i1.37

Zohar, D. (2010). Thirty years of safety climate research: Reflections and future directions. Accident Analysis \& Prevention, 42(5), 1517-1522. http://dx.doi.org/10.1016/j.aap.2009.12.019 
Sakariyau, O. B., \& Latip, H. A. 